\title{
An index to quantify street cleanliness
}

\author{
M. Zamorano \\ Department of Civil Engineering, Area of Environmental Technology, \\ University of Granada, Spain
}

\begin{abstract}
Street cleaning is an important facet of any solid waste management system, and is directly related to public education and behaviour. Litter deposited on the streets creates a negative visual impact, particularly on visitors. This indirectly affects the economy and human health of the city. Unfortunately, very little information is available in the literature on methods to quantify street cleanliness. The Federación Española de Municipios y Provincias (Spanish Federation of Municipalities and Provinces) has defined an index to evaluate the quality of the street cleaning operations in its Guia Técnica para la Gestión de Residuos Municipales y Limpieza Viaria (Technical Guide for Municipal Waste Management and Street Cleaning). The Cleanliness Index varies in proportion to the amount of litter on the street, but it is also related to the type of pavement, climate conditions, and vehicle parking mode. This Cleanliness Index was used to evaluate the dirtiness of a street in the city centre of Granada over an eight-day period, at different times. This evaluation also took into account the activities of the street population as well as manual sweeping practices. Since high levels of cleanliness were detected in this street during the day, it was concluded that the organization of manual sweepers is an important part of an effective system, and depends on the frequency of sweeping. However, after the last sweeping event, the dirtiness level increased considerably. Climate conditions during the study increased the number people on the street at the end of the day, which resulted in a higher value of the Cleanliness Index.
\end{abstract}

Keywords: street cleaning, litter, cleanliness level, Cleanliness Index.

\section{Introduction}

Urban surfaces receive waste deposits from natural and human sources. These sources include green urban areas and parks, vehicle traffic, industries, waste 
incineration, domestic heating and waste received through atmospheric transport, as well as from local human activities [1].

The waste deposited on the streets typically consists of soil, sediment, small pieces of pavement, leaves, and trash [2]. They create a negative visual impact, particularly on visitors, and thus indirectly affect the economy of the city [3]. However, urban street surfaces have also been identified as potentially significant contributors to water and air pollution, both as sources of chemical contaminants and as pathways for the transport of pollutants originating from adjacent land areas $[4,5]$.

The cleanliness of city streets is directly related to the city's public image [3]. This means that significant human and financial efforts are devoted to cleaning the street network in order to control litter and to provide suitable aesthetic and sanitary conditions. Street deposits have been mostly sampled by sweeping $[6,7]$, brushing $[8,9]$, vacuum $[10,11]$ or water flows, leading to the entry of water and pollutant loads into the combined sewer system [12].

However, the street cleanliness level is only one facet of a solid waste management system in which public education and public relations play critical roles [3]. Unfortunately, very little information is available in the literature on the various aspects associated with street cleanliness level. The "Scorecard" system of rating the cleanliness of city streets estimated the fraction of total street length that was acceptably clean, based on selected samples. A parametric model was tested that combined 12 variables related to the street cleaning programme of New York City, including workers assigned to street cleaning and tickets for sanitary code violations [3]. The Federación Española de Municipios $y$ Provincias (Spanish Federation of Municipalities and Provinces) has defined an index to evaluate the quality of the different street cleaning services in the Guía Técnica para la Gestión de Residuos Municipales y Limpieza Viaria (Technical Guide for Municipal Waste Management and Street Cleaning). This index varies in proportion to the amount of litter on the street, but it is also related to the type of pavement, climate conditions or vehicle parking mode [13].

This paper shows the application of the Cleanliness Index as defined by the FEMP guide [13] to measure the effectiveness of the street sweeping services. For this purpose, we monitored the amount of litter in a street in the city centre of Granada during a one-week period.

\section{Material and methods}

\subsection{Cleanliness Index definition}

The Cleanliness Index (CI) is defined by equation (1), where $\lambda$ and $n$ are correction factors considering conditions affecting cleanliness level; $C$ is the weighted quantity of litter; and $S$ is the observation area [13]. Originally this index was defined to determine the quality of the cleaning operation. In this research study, it was adapted to calculate the cleanliness level. Table 1 shows the classification index.

$$
C I=\frac{\lambda \times C}{n \times S} \times 1000
$$


Table 1: Cleanliness Index classification.

\begin{tabular}{|c|c|}
\hline Cleanliness Index values & Cleanliness level \\
\hline $\mathrm{CI}<70$ & Very high \\
\hline $70 \leq \mathrm{CI}<100$ & High \\
\hline $100 \leq \mathrm{CI}<150$ & Medium \\
\hline $150 \leq \mathrm{CI}<200$ & Low \\
\hline $\mathrm{CI} \geq 200$ & Very low \\
\hline
\end{tabular}

Table 2: $\quad$ Equivalent width [13].

\begin{tabular}{|l|c|c|c|c|}
\hline \multicolumn{1}{|c|}{\begin{tabular}{c} 
Real width of sidewalk $(\mathrm{m})$ \\
\cline { 2 - 5 }
\end{tabular}} & \multicolumn{4}{c|}{$\begin{array}{c}\text { Equivalent width } \\
\text { (m) }\end{array}$} \\
\cline { 2 - 5 } & $<2$ & $<5$ & $<7$ & $<10$ \\
\hline Free parking & 3 & 5 & 6 & 8 \\
\hline Parallel parking & 5 & 7 & 8 & 11 \\
\hline Perpendicular and angle parking & 7 & 9 & 10 & 12 \\
\hline
\end{tabular}

\subsubsection{The observation area}

The observation area $(S)$ included a whole section of road/sidewalk, on only one side or both sides of the road, where the cleanliness level was going to be measured. It was calculated by using equation (2), where $L$ is the total length of the observation area considered and $E$ is the equivalent width. The length of the observation area varied, depending on the equivalent width. In any case, the observation area was between 300 and $500 \mathrm{~m}^{2}$. The equivalent width depended on two factors: the real width of the sidewalk and the parking mode, according to Table 2.

$$
S\left(m^{2}\right)=L(m) \times E(m)
$$

\subsubsection{Correction factors}

The cleanliness level depends on both the climate conditions and the characteristics of the road/sidewalk considered in the evaluation. Two correction factors were included in the determination.

- $\lambda$. This correction factor takes into account climatic conditions and the conservation state of the pavement. Table 3 shows the values of $\lambda$.

- Number of extraordinary circumstances (n). This includes certain characteristics or circumstances at the observation area. For example, the existence of a bus stop increases the quantity of litter. This factor could have a value between 1 and 2, where value 1 is the absence of situations that increase the presence of waste in the area.

\subsubsection{Quantity of litter}

To quantify the litter in the observation area, it was necessary to count litter fractions. The classification in Table 4 was considered. Finally, the quantity of 
Table 3: $\quad$ Values of correction factor $\lambda[13]$.

\begin{tabular}{|l|c|c|c|c|}
\hline Type of pavement & Conservation state & \multicolumn{3}{|c|}{ Wind and rain } \\
\cline { 3 - 5 } & & Low & Medium & High \\
\hline \multirow{2}{*}{ Asphalt } & Good & 1 & 0.8 & 0.6 \\
\cline { 2 - 5 } & Bad & 0.9 & 0.7 & 0.5 \\
\hline Sand & & 0.8 & 0.6 & 0.5 \\
\hline
\end{tabular}

Table 4: $\quad$ Litter classification and weighting values [13].

\begin{tabular}{|l|l|c|}
\hline Litter classification & Weighting values \\
\hline \multirow{3}{*}{ Inorganic } & Small & 1 \\
\cline { 2 - 3 } & Medium size & 2 \\
\cline { 2 - 3 } & Large & 4 \\
\hline \multirow{3}{*}{ Organic } & Small & 2 \\
\cline { 2 - 3 } & Medium size & 4 \\
\cline { 2 - 3 } & Large & 6 \\
\hline \multirow{2}{*}{ Trash } & With litter & 3 \\
\cline { 2 - 3 } & Empty & 0 \\
\hline \multirow{2}{*}{ Tree basins } & Uncleaned & 6 \\
\cline { 2 - 3 } & Clean & 0 \\
\hline Uncollected sweeping waste & 6 \\
\hline \multicolumn{2}{|l|}{ Tree leaves } & \multicolumn{2}{|c|}{1} \\
\hline \multicolumn{2}{|l|}{ Animal droppings } & 3 \\
\hline \multicolumn{2}{|l|}{ Sticky residue on the pavement } & 2 \\
\hline
\end{tabular}

litter of each type was multiplied by a weighting coefficient that depended on the litter classification (Table 4).

\subsection{Characteristics of the street studied}

The street chosen in this study is named Alhamar. It is located in the centre of the city of Granada (Figure 1). It is a public urban street characterized by high population density, low commercial level, presence of some bars, restaurants and leisure areas, high vehicle traffic intensity, medium pedestrian traffic intensity, a 3-meter-width sidewalk with a curbside, concrete paving stones, parallel parking area near the sidewalk, and pavement in a good state of conservation. Cleaning operations consisted of manual sweeping three times a day, seven days a week.

\subsection{Sampling programme}

Seven evaluations of the cleanliness level per day over an eight-day period (20-27 July 2009) were performed before and after sweeping operations. Three randomly observed areas were considered in each determination to obtain an average value of the Cleanliness Index of the street per evaluation. The exact time of the evaluation were chosen, based on the time of the cleaning operation. 


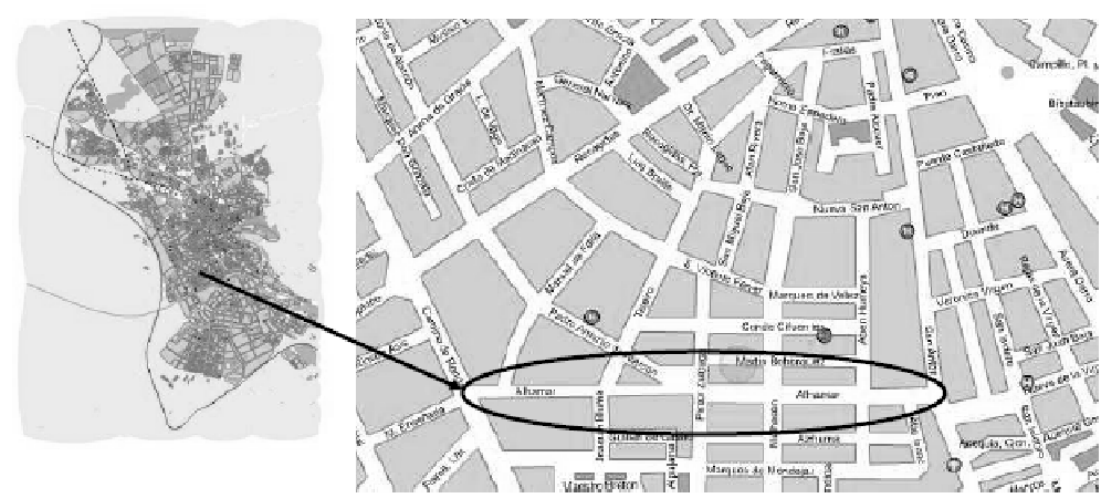

Figure 1: Location of the street studied.

The monitoring times were the following: 8:30, 9:30, 13:30, 14:30, 17:30, 18:30 and 23:30.

\section{Results and discussion}

\subsection{An example of Cleanliness Index calculation}

To illustrate the calculation procedure, this section describes how the Cleanliness Index was obtained. The determination selected was performed on 27 July at $8: 30$.

\subsubsection{The observation area}

The sidewalk of the street was within 3 meters with parallel parking along both sides of the pavement near the curbside. This meant an equivalent sidewalk width of $7 \mathrm{~m}$ (Table 2). Since the length of the observation area was $60 \mathrm{~m}$, the surface (S) was $420 \mathrm{~m}^{2}$, which was within the established interval $\left(300-500 \mathrm{~m}^{2}\right)$.

\subsubsection{Correction factors}

Concrete paving stones in a good state of conservation and mild climate conditions during the day gave a $\lambda$ value of 1 , as shown on Table 3 . Since no extraordinary circumstances were detected in the observation area, the correction factor was given the minimum value $(n=1)$.

\subsubsection{Quantity of litter}

The number of different litter fractions in the area was counted. The results are shown in Table 5.

\subsubsection{Cleanliness Index}

Based on the previous results, the Cleanliness Index (CI) was calculated with Equation (1), and the following result was obtained: 
Table 5: $\quad$ Counting results and final weighting values.

\begin{tabular}{|l|l|c|c|c|}
\hline \multirow{2}{*}{ Litter classification } & $\begin{array}{c}\text { Weighting } \\
\text { coefficient }\end{array}$ & $\begin{array}{c}\text { Counting } \\
\text { results }\end{array}$ & $\begin{array}{c}\text { Final } \\
\text { values }\end{array}$ \\
\hline \multirow{3}{*}{ Inorganic } & Small & 1 & 23 & 23 \\
\cline { 2 - 5 } & Medium size & 2 & 0 & 0 \\
\cline { 2 - 5 } & Large & 4 & 0 & 0 \\
\hline \multirow{3}{*}{ Organic } & Small & 2 & 0 & 0 \\
\cline { 2 - 5 } & Medium size & 4 & 0 & 0 \\
\cline { 2 - 5 } & Large & 6 & 0 & 0 \\
\hline \multirow{3}{*}{ Trash } & With litter & 3 & 2 & 6 \\
\cline { 2 - 5 } & Empty & 0 & 0 & 0 \\
\hline \multirow{2}{*}{ Tree } \\
basins & Uncleaned & 6 & 2 & 12 \\
\cline { 2 - 5 } & Clean & 0 & 0 & 0 \\
\hline \multicolumn{2}{|l}{ Uncollected sweeping waste } & 6 & 0 & 0 \\
\hline \multicolumn{2}{|l|}{ Tree leaves } & 1 & 0 & 0 \\
\hline \multicolumn{2}{|l|}{ Animal droppings } & 3 & 0 & 10 \\
\hline \multicolumn{2}{|l|}{ Sticky residue on the pavement } & 2 & 5 & $\mathbf{5 1}$ \\
\hline \multicolumn{2}{|l|}{ Total } & & & 0 \\
\hline
\end{tabular}

$$
C I=\frac{(1 \times 51)}{1 \times 420} \times 1000=121.4
$$

The procedure described was repeated in two more areas, which were found to have Cleanliness Index values of 98.3 and 108.7, respectively. At 8:00 A.M. before the cleaning operation, the average value for the day considered was 109.5. This value was regarded as a medium Cleanliness Index (Table 1).

The same procedure was followed to determine the Cleanliness Index for the rest of the days and hours.

\subsection{General results}

Table 5 and Figure 2 show the Cleanliness Index values of the street at different times over a period of eight days, and Table 6 classifies the cleanliness level in each case. Bold values correspond to the Cleanliness Index determined after sweeping the street. The analysis of results led to the following conclusion:

- The cleanliness level of the area in the early hours of the day, before the first cleaning operation, was usually higher than 100 . Thus, it was classified as low.

- After the first cleaning operation, in the morning, the index always had values lower than 70. It was thus classified as very high.

- The amount of litter always increased during the final hours of the day. Consequently the level of cleanliness at the beginning of the next day was generally low. 
Table 6: Average Cleanliness Index values.

\begin{tabular}{|c|c|c|c|c|c|c|c|c|}
\hline Time & Mon & Tues & Wed & Thurs & Fri & Sat & Sun & Mon \\
\hline $8: 30$ & 95.2 & 303.5 & 159.5 & 139.2 & 131.3 & 174.2 & 93.3 & 109.5 \\
\hline $\mathbf{9 : 3 0}$ & $\mathbf{1 0 . 2}$ & $\mathbf{1 9 . 0}$ & $\mathbf{3 6 . 0}$ & $\mathbf{1 9 . 0}$ & $\mathbf{2 4 . 1}$ & $\mathbf{2 2 . 7}$ & $\mathbf{7 . 7}$ & $\mathbf{1 2 . 2}$ \\
\hline $13: 30$ & 74 & 43.2 & 71.4 & 60.0 & 80.4 & 48.2 & 59.2 & 60.7 \\
\hline $\mathbf{1 4 : 3 0}$ & $\mathbf{1 1 . 3}$ & $\mathbf{7 . 5}$ & $\mathbf{1 2 . 3}$ & $\mathbf{8 . 9}$ & $\mathbf{2 . 5}$ & $\mathbf{8 . 4}$ & $\mathbf{1 2 . 4}$ & $\mathbf{1 0 . 4}$ \\
\hline $17: 30$ & 69.8 & 54.6 & 53.8 & 36.1 & 57.4 & 29.7 & 31.9 & 94.2 \\
\hline $\mathbf{1 8 : 3 0}$ & $\mathbf{8 . 9}$ & $\mathbf{8 . 8}$ & $\mathbf{2 8 . 6}$ & $\mathbf{1 0 . 3}$ & $\mathbf{2 1 . 4}$ & $\mathbf{5 . 9}$ & $\mathbf{2 . 4}$ & $\mathbf{7 . 1 4}$ \\
\hline $23: 30$ & 189.4 & 102.6 & 114.3 & 112.6 & 138.7 & 74.4 & 83.5 & 114.2 \\
\hline
\end{tabular}

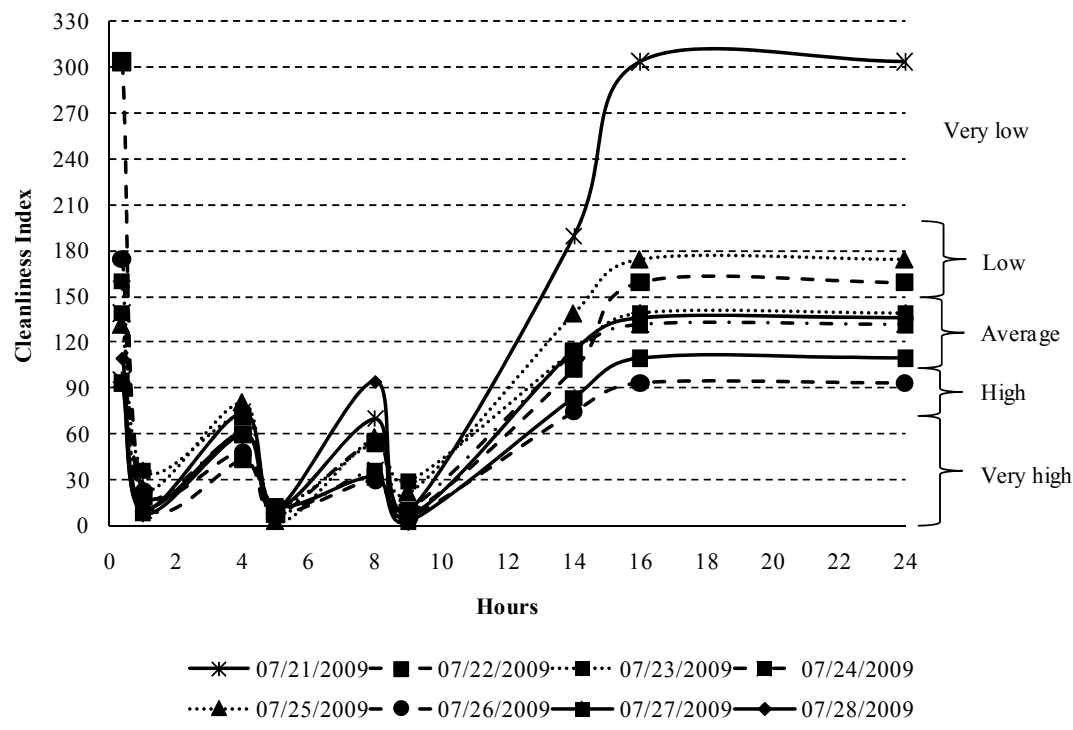

Figure 2: Cleanliness Index of the street studied.

Table 6, in bold, shows the index values after the street was swept. The analysis of the results provided the following conclusions:

- There was a substantial relationship between the cleaning workforce and street cleanliness [3]. The street cleaners swept the street three times a day, and in consequence, the cleanliness level of the street was very high during most of the day.

- The cleaning workforce operated very efficiently. The Cleanliness Index after cleaning operations was always very high regardless of the quantity of litter on the street.

Figure 3 shows the average values of the Cleanliness Index which were calculated during the eight days of the study. It also gives values $\mathrm{L}_{1}, \mathrm{~L}_{2}$ and $\mathrm{L}_{3}$, which are the litter rate or the increase in dirtiness of the street between the first and second cleaning operations; the second and third cleaning operations; and after the last cleaning operation, respectively. The litter rate showed similar 
values $\left(\mathrm{L}_{1}=14.425, \mathrm{~L}_{2}=14.408\right.$, and $\left.\mathrm{L}_{3}=20.9065\right)$, though after the last cleaning operation it increased slightly.

Throughout the day, average index values were lower than 70 . After the last cleaning operation and after 2.8 hours (point $a$ in Figure 3), the index was higher than 70 (point $b$ in Figure 3); after 4.2 hours, it reached 100 (point $c$ in Figure 3), thus classifying the Cleanliness Index as average. At approximately 24:00 the index reached the maximum value.

The sampling date corresponded to the summer season when there were very high temperatures in the city. In the afternoon hours, high temperatures reduced the number of people walking on the street, and consequently, the quantities of litter decreased [3]. However, in the evening when temperatures cooled, the population went out to restaurants and bars. Various leisure areas are located on the street of our study. This meant that there were people on the street until late at night, which increased the quantity of litter.

These variations in the cleanliness level could be explained by all of the previously mentioned factors. However, new studies would be necessary to analyze the Cleanliness Index at different times of the year and on other streets in order to confirm the preliminary results and conclusions of this study.

Table 7: $\quad$ Classification of the Cleanliness Index.

\begin{tabular}{|c|c|c|c|c|c|c|c|c|}
\hline Time & Mon & Tues & Wed & Thurs & Fri & Sat & Sun & Mon \\
\hline $8: 30$ & H & VL & L & L & L & L & H & L \\
\hline $\mathbf{9 : 3 0}$ & VH & VH & VH & VH & VH & VH & VH & VH \\
\hline $13: 30$ & H & VH & H & VH & H & VH & VH & VH \\
\hline $\mathbf{1 4 : 3 0}$ & VH & VH & VH & VH & VH & VH & VH & VH \\
\hline $17: 30$ & VH & VH & VH & VH & VH & VH & VH & H \\
\hline $\mathbf{1 8 : 3 0}$ & VH & VH & VH & VH & VH & VH & VH & VH \\
\hline $23: 30$ & L & L & L & L & L & H & H & L \\
\hline
\end{tabular}

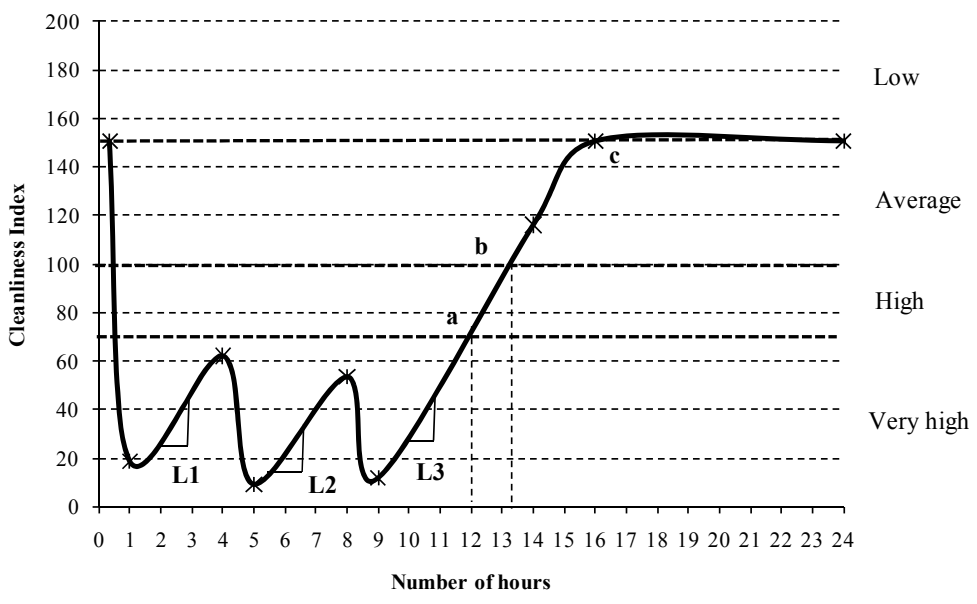

Figure 3: Average Cleanliness Index values. 


\section{Conclusions}

This research showed that the Cleanliness Index defined by the Spanish Federation of Municipalities and Provinces in its Guía Técnica para la Gestión de Residuos Municipales y Limpieza Viaria, to evaluate the quality of cleaning operations, could also be applied to quantify the cleanliness level of streets.

In this study, the index was applied to calculate the amount of litter at different hours of a day during one week in a highly populated area in Granada (Spain). As a result, high levels of cleanliness were detected in this street during the day. It was thus possible to conclude that the organization of manual sweepers and the frequency of sweeping were effective. However after the last sweeping operation, the dirtiness level in the street increased considerably. This could be explained by the fact that because of the cooler temperatures, more people went outside in the evening to have fun and go to the leisure areas in the city.

The results obtained corresponded to the first stage of our research study. The next step is to increase the number of streets to be analyzed as well as the sampling frequency. One of the project outcomes will be a model that can be used to predict the cleanliness level in the streets, and which will help to plan the organization of cleaning operations.

\section{Acknowledgements}

This research was partially funded by the Innovation and Science Division of the Andalusian Regional Government (Research Project TIC-02913) and the research group, Approximate Reasoning and Artificial Intelligence (ARAI-TIC 111), of the University of Granada.

\section{References}

[1] Brisa F.J., Garnauda, S., Apperrya, N., Gonzaleza, A., Mouchel, J.M., Chebbob, G. \& Thévenota, D.R. 1999. A street deposit sampling method for metal and hydrocarbon contamination assessment. The Science of the Total Environment, 235, 211-220.

[2] Jang, Y-C., Jain, P., Tolaymat, T., Dubey, B. \&Townsend, T. 2009. Characterization of pollutants in Florida street sweepings for management and reuse. Journal of Environmental Management, 91, 320-327.

[3] Riccio, L.J., Miller, J. \& Bose, G. 1988. Polishing the big apple models of how manpower utilization affects street cleanliness in New York city. Waste Management \& Research, 6, 163-174.

[4] Gertler, A., Kuhns, H., Abu-Allaban, M., Damm, C., Gillies, J., Etyemezian, V., Clayton, R. \& Proffitt, D. 2006. A case study of the impact of Winter road sand/salt and street sweeping on road dust re-entrainment. Atmospheric Environment 40, 5976-5985.

[5] Irvine K.N., Perrelli, M.F., Ngoen-klan, R. \& Droppo, I.G. 2009. Metal levels in street sediment from an industrial city: spatial trends, chemical 
fractionation, and management implications. Journal of Soils Sediments, 9 , 328-341.

[6] Ogunsola, O.J., Oluwole, A.F. \& Asubiojo, O.I 1994. Traffic pollution: preliminary elemental characterisation of roadside dust in Lagos, Nigeria. Science of the Total Environment, 146/147, 175-184.

[7] Al-Rajhi, M.A., Seaward, M.R.D. \& Al-Aamer, A.S. 1996. Metal levels in indoor and outdoor dust in Riyadh, Saudi Arabia. Environment International, 22, 315-324.

[8] Davies, D.J.A, Watt, J.M. \& Thorton, I. 1987. Lead levels in Birmingham dusts and soils. Science the Total Environment, 67, 177-185.

[9] Culbard, E.B. \& Thornton, I. 1988. Metal contamination in British urban dusts and soils. Journal of Environmental Quality, 17, 226-234.

[10] Butler, D., Thedchanamoorthy, S. \& Payne, J.A. 1992. Aspects of surface sediment characteristics on an urban catchment in London. Water Science and Technology, 25, 13-19.

[11] Ball, J.E, Jenks, R. \& Aubourg, D. 1996. Dry weather build-up of constituents on road surfaces. Seventh International Conference on Urban Storm Drainage. Hanover, Germany.1996:785-790.

[12] Gromaire-Mertz, M.C., Chebbo, G., Saad, M. 1998. Origins and characteristics of urban wet weather pollution in combined sewer systems: the experimental urban catchment 'Le Marais' in Paris. Water Science and Technology, 37, 35-48.

[13] FEMP (Federación Española de Municipios y Provincias-The Spanish Federation of Municipalities and Provinces). Guía Técnica para la Gestión de Residuos Municipales y Limpieza Viaria (Technical Guide for Municipal Waste Management and Street Cleaning). FEMP. 2008. 